\title{
Farmers' knowledge of export criteria of onion crop in Luxor governorate, Egypt
}

\author{
Shakwar H. A. M. A.*, Abdelhalim M. F. I. \\ Department of Agricultural Extension and Rural Sociology, Faculty of Agriculture, Al-Azhar University, Assiut, Egypt
}

\begin{abstract}
The main objectives of this research were: a) Determine respondents' farmers level of knowledge of the export criteria of onion crop. b) Identify the problems that face of them. c) Determine relationship between level of their knowledge of these criteria and their personal variables. This research was conducted of a simple random sample of 144 respondents from the villages Tomas Al-Bahria and Al-Dair in Esna district, Luxor, Egypt. Data were collected using a questionnaire by interpersonal interviews during February and March 2021. Data were analyzed using tables, frequencies, percentage, and Spearman rank correlation coefficient, using package of statistical programs of social sciences (SPSS). The results showed that:

○ $51.3 \%$ of respondents had high knowledge level of quality criteria, $77.1 \%$ had low knowledge level of size criteria, $80.6 \%$ had middle knowledge level of showing criteria and $60.4 \%$ had low knowledge level of marks criteria.

○ $\quad 89.6 \%$ of respondents had middle knowledge level of export criteria of onion crop, while this level high of $10.4 \%$.

- The most important problems facing the respondents: agricultural extension is not interested in providing information on export criteria of onion crop, decrease of cooperative association for accumulation onion designed for export, price of the dry onion had low, and decrease information of onion criteria designed for export.

- Significant positive correlations were found between respondents' knowledge level of export criteria of onion crop and some independent variables and Significant negative correlation were found between respondents' knowledge level of export criteria of onion crop and some independent variables.
\end{abstract}

Keywords: knowledge, export criteria, onion, Luxor.

* Corresponding author: Shakwar H. A. M. A., 


\title{
معرفة الزراع بالمواصفات التصديرية لمحصول البصل بمحافظة الأقصر بجمهورية مصر العربية
}

\author{
حسن عبد العاطى محمد أحمد شقور ، محمد فتحي إسماعيل عبدالحليم \\ قسم الارشاد الزر اعى والمجتمع الريفي ، كلية الزراعة ، جامعة الأزهر (فرع أسيوط) ، أسيوط ، جمهورية مصر العربية
}

استهدف هذا البحث تحديد مستوى معرفة الزراع المبحوثين بالمواصفات التصديرية لمحصول البصل, والتعرف على المشكلات التي تواجه

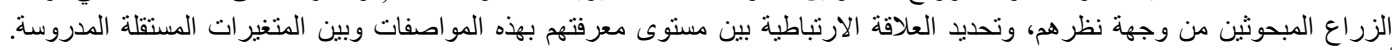

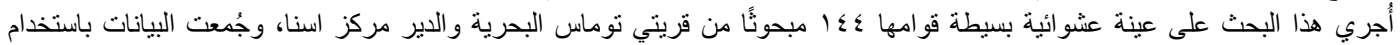

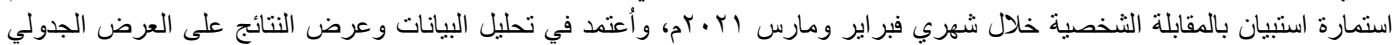

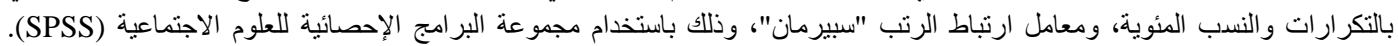
وجاءت أهم نتائج البحث على النحو التالي:

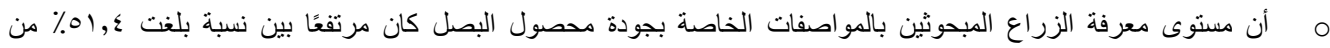

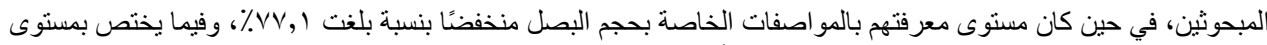

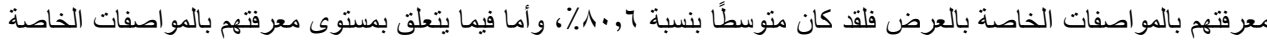

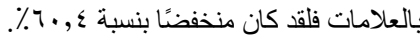

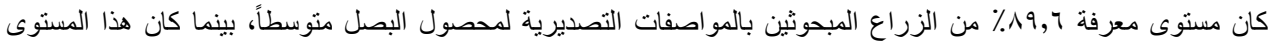

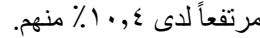

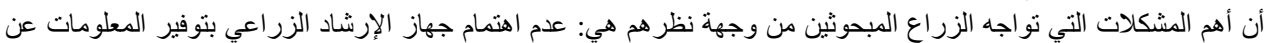

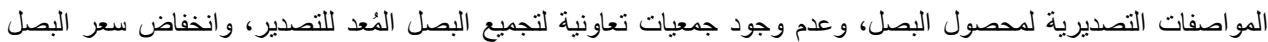

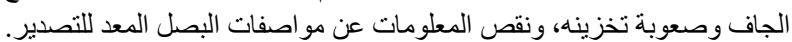

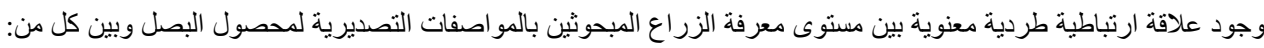

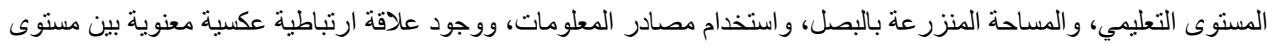

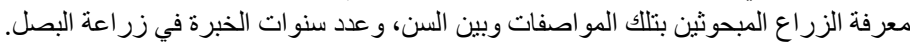




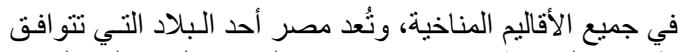

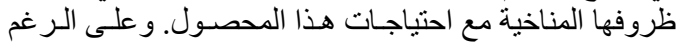

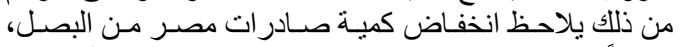

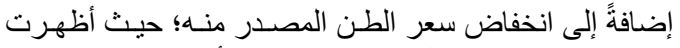

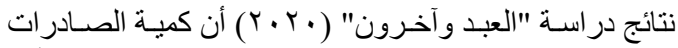

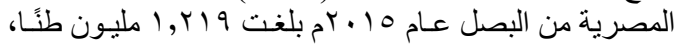

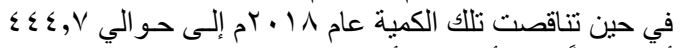

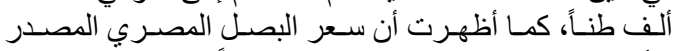

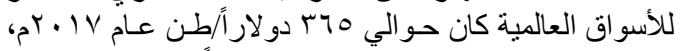

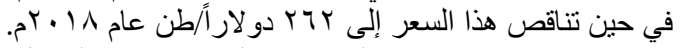

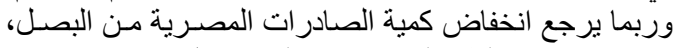

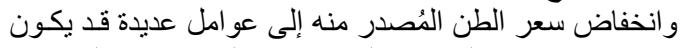
منها نقص معرفة الززر اع بالمو اصـفات التصـديرية (القياسـية)

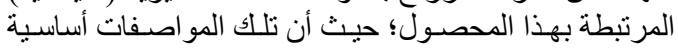

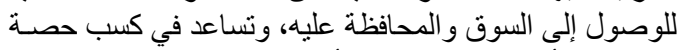

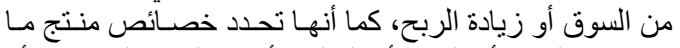

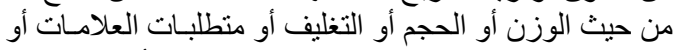

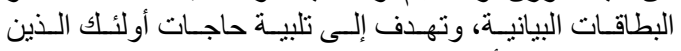

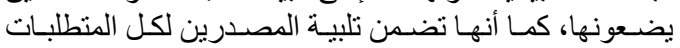

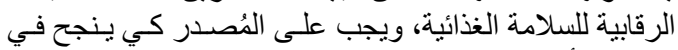

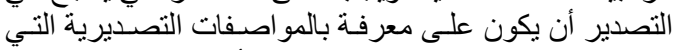

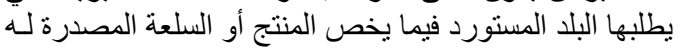

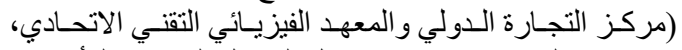

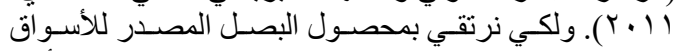

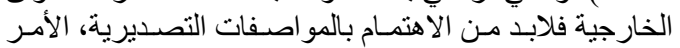

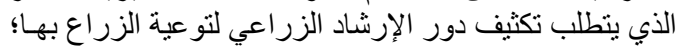

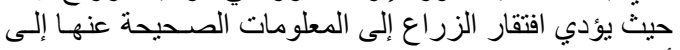

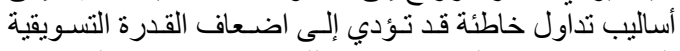

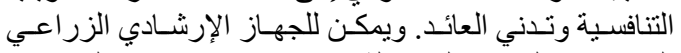

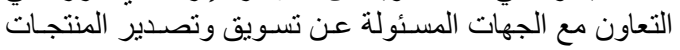

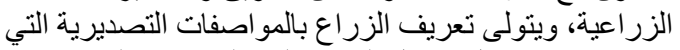

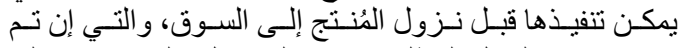

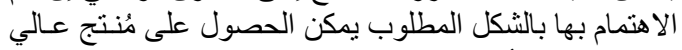

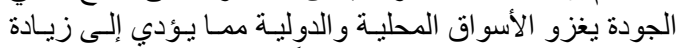

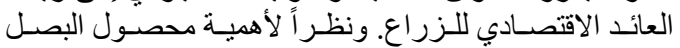

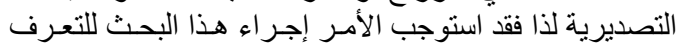

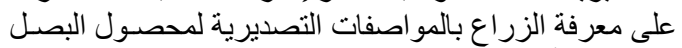

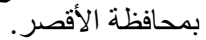

\section{أهداف البحث}

اتساقاً مع مشكلة البحث فقد تحددث أهدافه في النقاط التالية: '. تحديد مستوى معرفة الزراع المبحوثين بالمواصفات

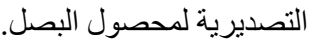

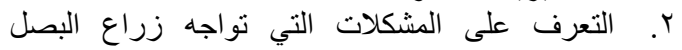
المبحوثين من وجهة نظر هم. r. تحديد العلاقة الارتباطية بين مستوى معرفة الزراع

\section{مقدمة البحث ومشكلته}

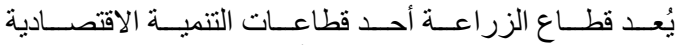

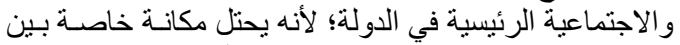

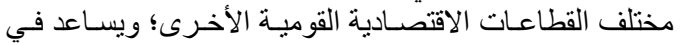

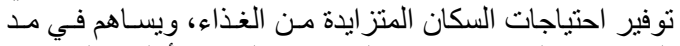

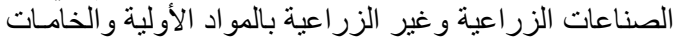

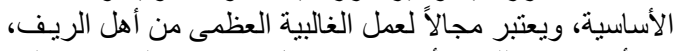

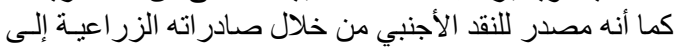

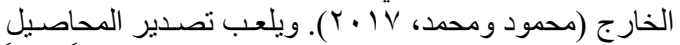

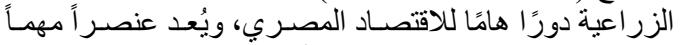

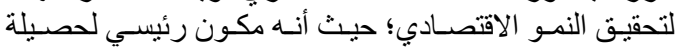

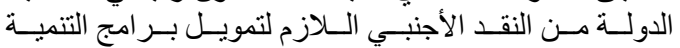

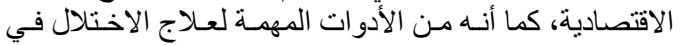

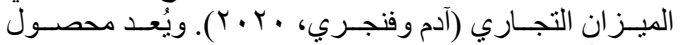

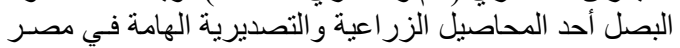

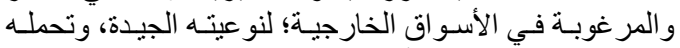

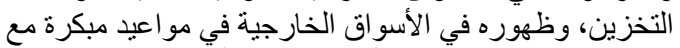

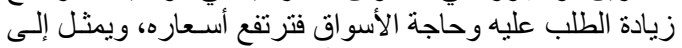

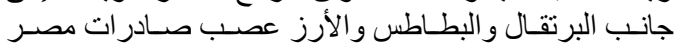

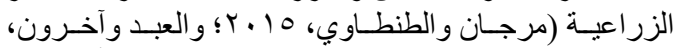

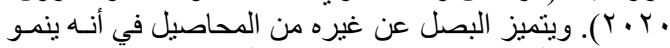

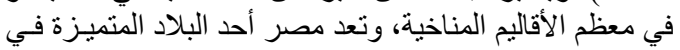

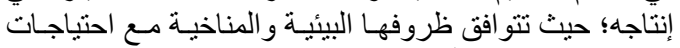

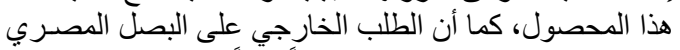

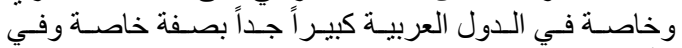

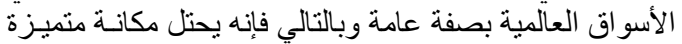

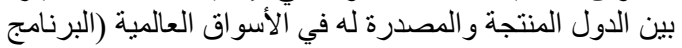

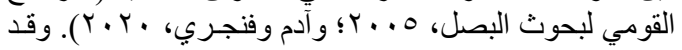

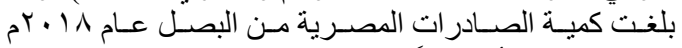

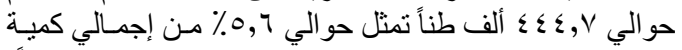

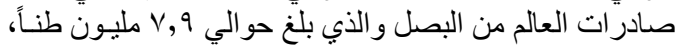

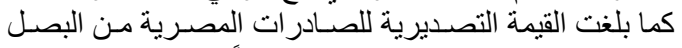

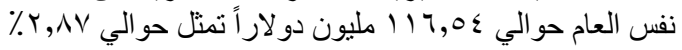

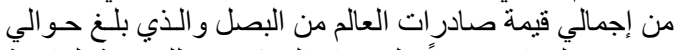

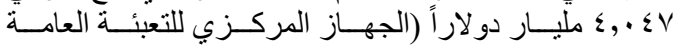

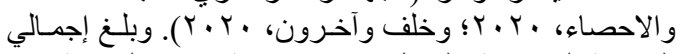

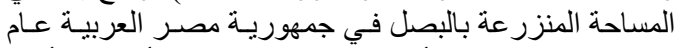

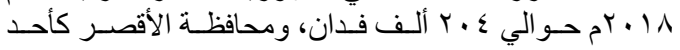

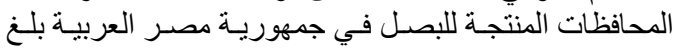

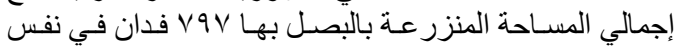

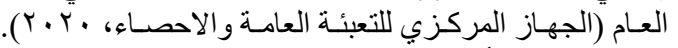

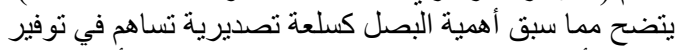

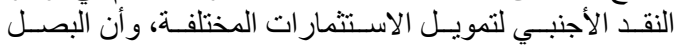

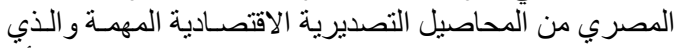

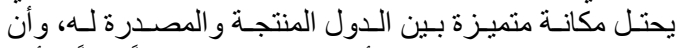

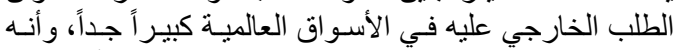

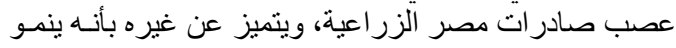


مبحوثاً من قرية نوماس البحرية، و 7T مبحوثاً من قرية الاير).

\section{ثالثاً: جمع البيانات}

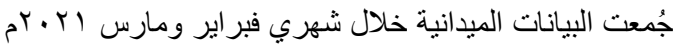
بالمقابلة الثخصية للزراع المبات المبحوثين، باستخدام استمارة

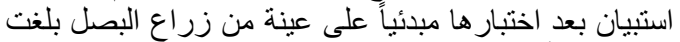

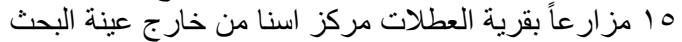

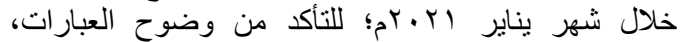

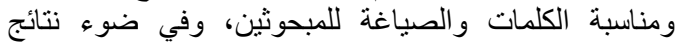

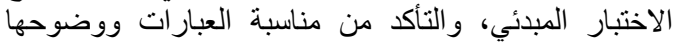

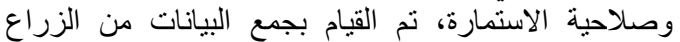

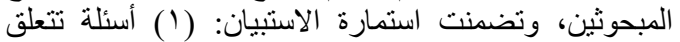

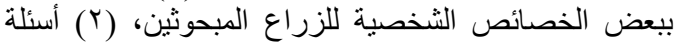

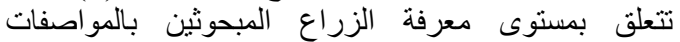
التصديرية لمحصول البصل، (ץ) أسئلة تتعلق بالمشكلات التئي تواجه زراع البصل المبحوثين.

رابعاً: المعالجة الكمية للبيانات

$$
\text { ا ـ المتغيرات المستقلة }
$$

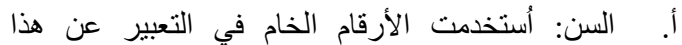
المتغير، وبحيث يتم تقسيم الزراع المباع المبحوثين إلى ثلاث

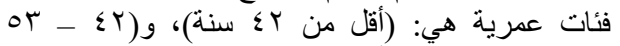

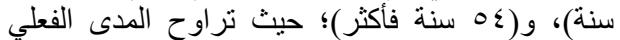
لأعمار المبحوثين ما بين • بـ ـ 70 سنة.

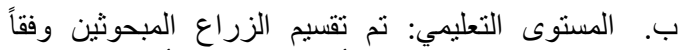

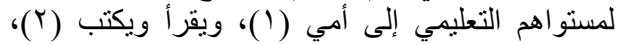

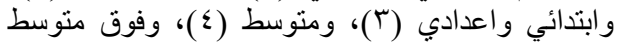

(0)، وجامعي (7).

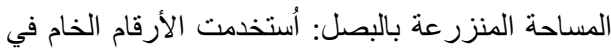

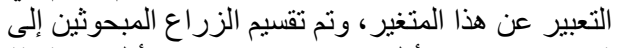

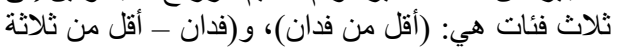
أفدنة)، و و(ثلاثة أفدنة فأكثر ).

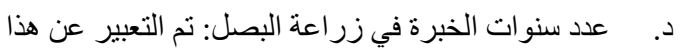

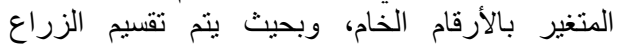

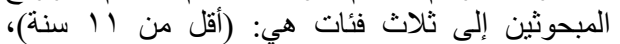
و(11 - V ا سنة)، و(1 اسنة فأكثر).

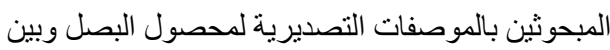

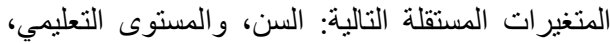

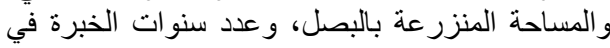
زر اعة البصل، واستخدام مصادر المعلومات.

\section{الفروض البحثية}

لتحقيق الهدف البحثي الثالث تم صياغة الفرض البحثني التالي:

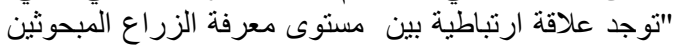

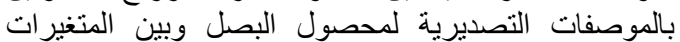

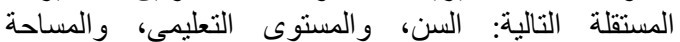

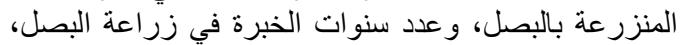

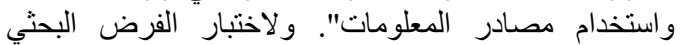

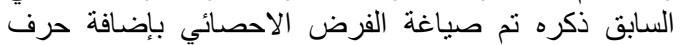
النفي "لا" أمام الفرض البحثي.

\section{الطريقة البحثية}

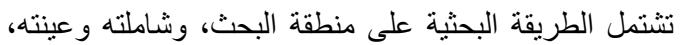
وجمع بياناته، والمعالجة الكمية للبيانات، وأدوات لثمات التحليل

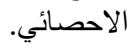

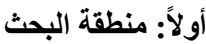

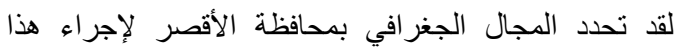

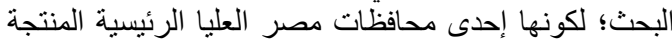

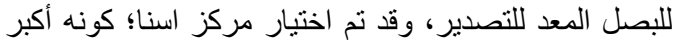

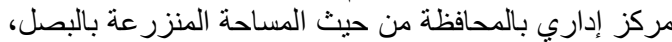

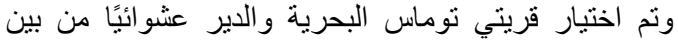

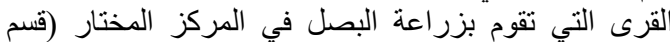

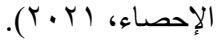

\section{ثانياً: شاملة البحث وعينته}

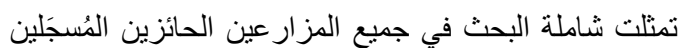

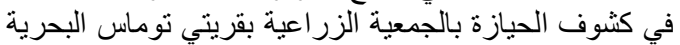

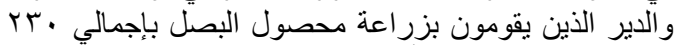

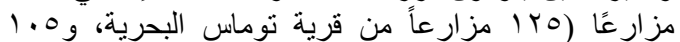

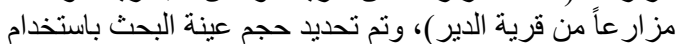

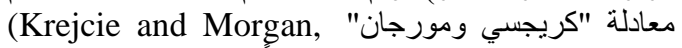

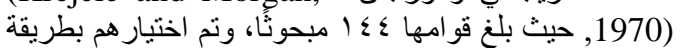

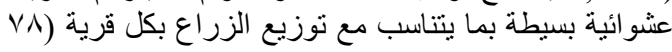




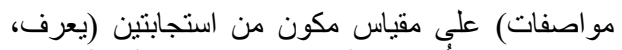

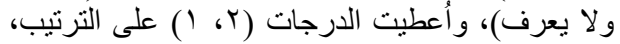

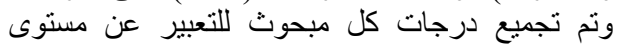

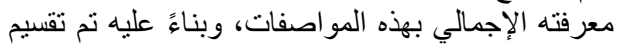

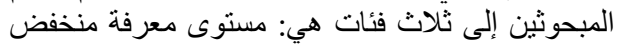

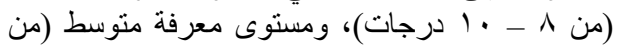

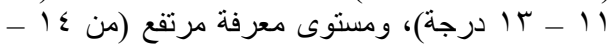

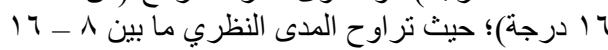
درجة.

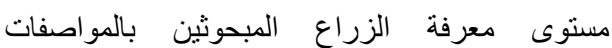

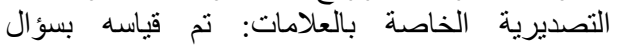

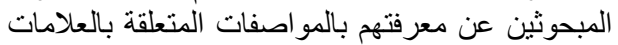

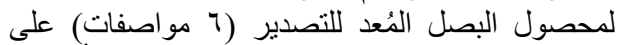

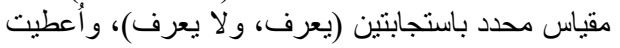

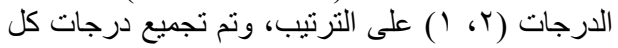

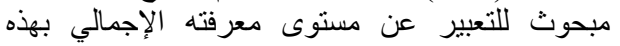

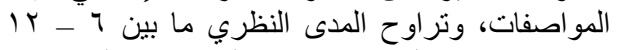

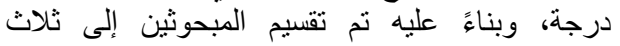

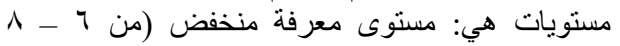

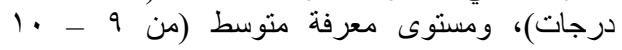

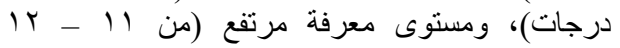
درجة).

ولحساب المستوى المعرفي الإجمالي للزراع المبحون المبنين

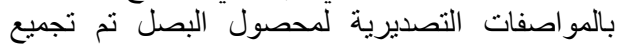

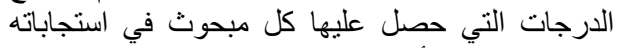

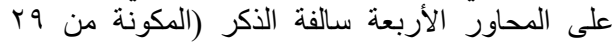

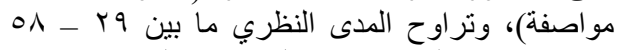

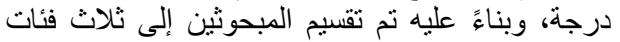

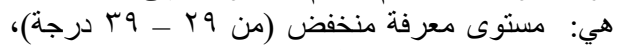

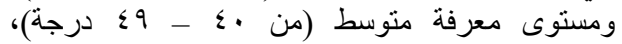
ومستوى معرفة مرتفع (من منون (من - 01 درجة).

بّ. المشكلات التي تواجه زراع البصل المبحوثين من وجهة نظرهم

تم حساب التكرارات والنسب المئوية لكل مشكلة ثم رتبت تناز لباً وفقاً لهذه التكر ارات وات.

\section{خامساً: أدوات التحليل الاحصائي}

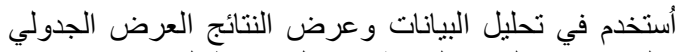

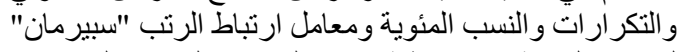

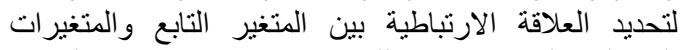

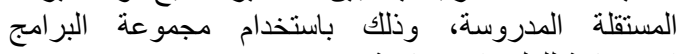

الاحصائية للعلوم الاجتماعية (SPSS).
• استخدام مصادر المعلومات: تم قياسه بسؤال المبحوثين

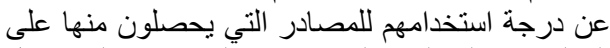

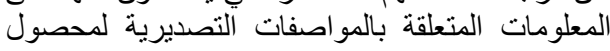

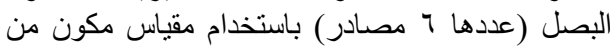

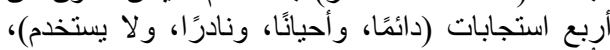

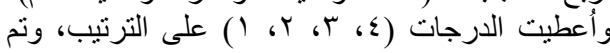

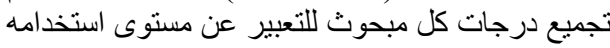

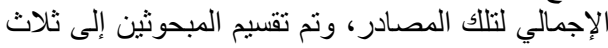

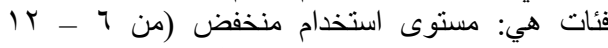

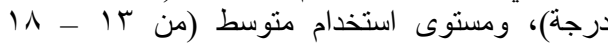

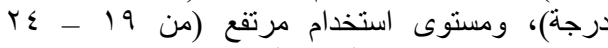
درجة)؛ حيث تراوح المدى النظري ما بين درجة.

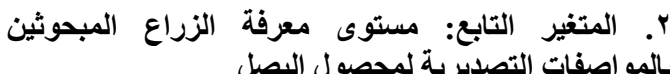
تم تقسيم هذا المتغير التابع إلى أربعة محاور على النحو التالي: بالئ

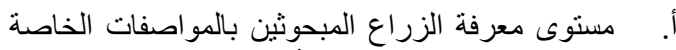

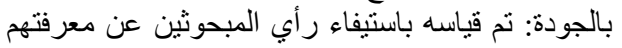

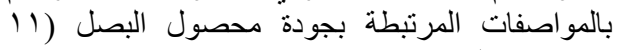

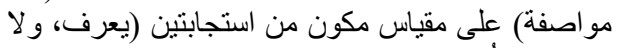

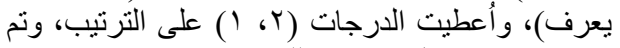

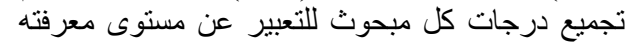

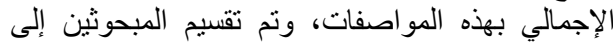

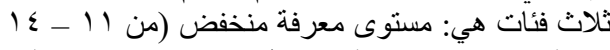

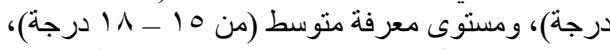

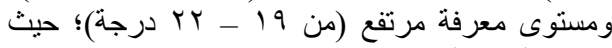

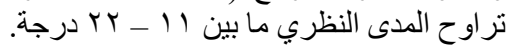

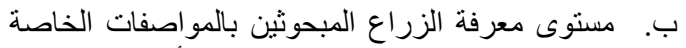
بالحجم داخل كل عبوة رنبة الدرجتان الأولى و الثانية: تم

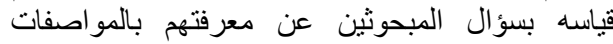

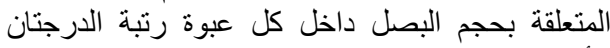

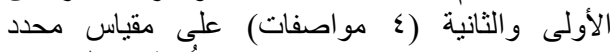

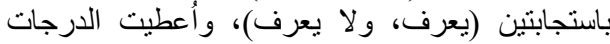

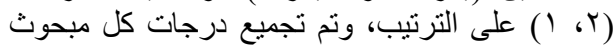

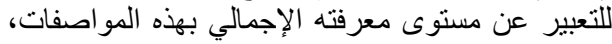

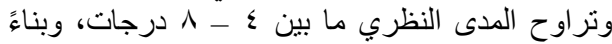

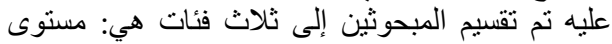

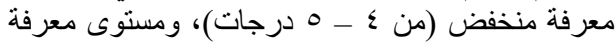

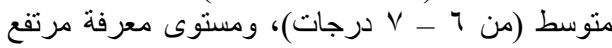

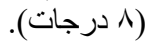

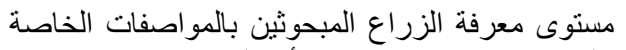

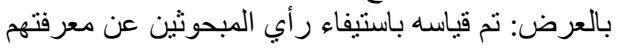

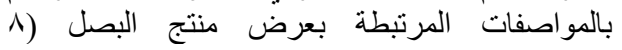




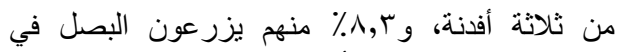

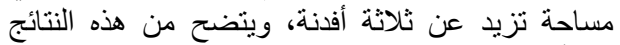

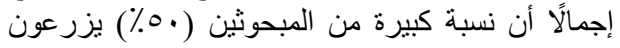

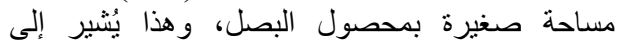
محدودية قدر اتهم المالية والإنتاجية.

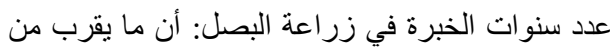

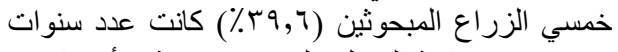

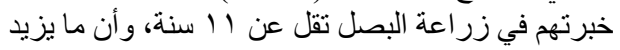

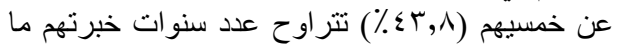

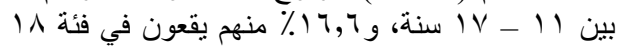

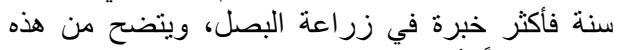

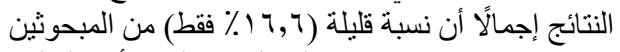

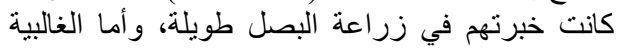

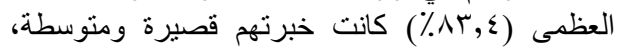

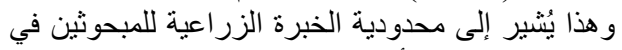

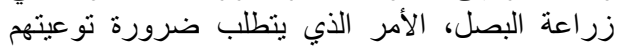

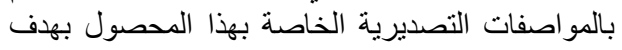
تحسين مستو اهم الاقتصادي ورفع مستوى معيشتهم.

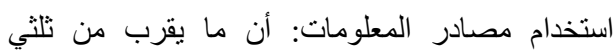

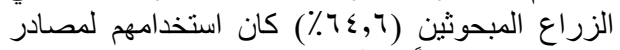

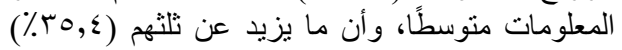

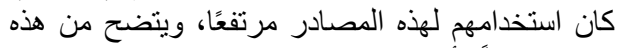

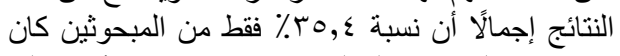

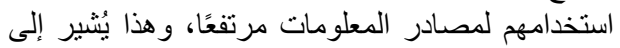

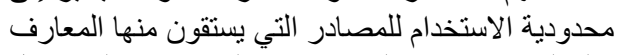

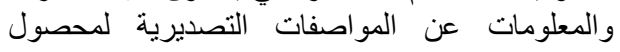
البصل، وربما يرجع ذللك لاعتمادهم الكبير على خبرتهم للهر

الثخصية.

\section{النتائج ومناقشثتها}

\section{أولا: وصف عينة البحث}

أوضحت النتائج الواردة بالجدول (1) و المتعلقة بوصف عينة

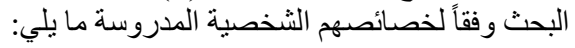

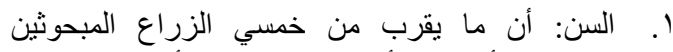

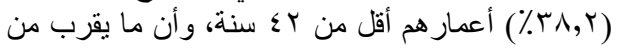

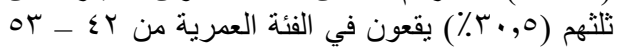

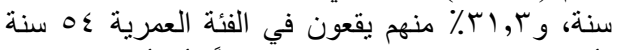

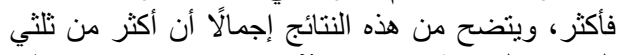

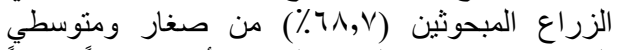
السن، وتعتبر هذه الفئات العمرية أكثر نشاطناً وتقبلاً

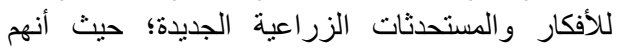
يقعون في المرحلة العمرية التي تتسم بالحيوية والنية النشاط

وبذل الجهد.

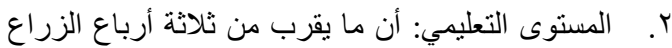

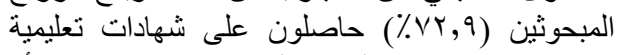

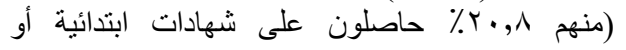

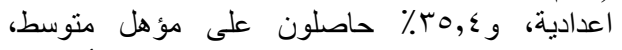

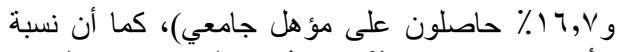

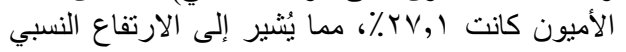
في المستوى التعليمي للزبر اع اع المبحوثين.

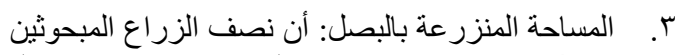

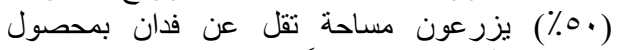

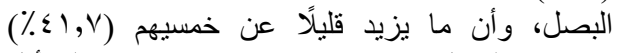
يزرعون البصل في مساحة تنز اوح ما بين فدان إلى أقلى

جدول ( (): التوزيع العددي و النسبي للزر اع المبحوثين وفقاً لخصائصهم الثخصية المدروسة (ن= ع ـ ().

\begin{tabular}{|c|c|c|c|c|c|c|}
\hline$\%$ & عدد & الخصائص الثخصبية & $\%$ & عدد & الخصائص الثخصية & \\
\hline & & \multirow{2}{*}{ ؛. عدد سنوات الخبرة في زراعة البصل: } & \multicolumn{4}{|c|}{ إـ السن: } \\
\hline & & & $r \Lambda, r$ & 00 & صغار السن (أقل من r؟ سنة). & - \\
\hline \multirow{2}{*}{$r q, 7$} & \multirow{2}{*}{ or } & \multirow{2}{*}{ قصيرة (أقل من ل 1 سنة). } & $r \cdot, 0$ & $\leqslant \leqslant$ & متوسطي السن (r؟ - ro سنة). & - \\
\hline & & & $r, r$ & £o & كبار السن (ع سنة فأكثر). & - \\
\hline$\varepsilon r, \Lambda$ & Tr & - - متوسطة (II - V ا سنة). & \multicolumn{4}{|c|}{ ب. المستوى التعليمي: } \\
\hline 17,7 & $r \leqslant$ & - - ـ طويلة (1/ سنة فأكثر). & $r v, 1$ & rq & أمي. & - \\
\hline & & \multirow{2}{*}{ 0. استخدام مصادر المعلومات: } & $r \cdot, \Lambda$ & $r \cdot$ & ابتدائي و اعدادي. & - \\
\hline & & & $r_{0, \varepsilon}$ & 01 & متوسط. & - \\
\hline \multirow{2}{*}{$\cdot, \cdot$} & \multirow{2}{*}{. } & \multirow{2}{*}{ منخفض (1 - Y ا درجة). } & $17, \mathrm{~V}$ & $r \varepsilon$ & جامعي & - \\
\hline & & & \multicolumn{4}{|c|}{ r. المساحة المنزر عة بالبصل: } \\
\hline \multirow{2}{*}{$T \leqslant, T$} & \multirow[t]{2}{*}{$9 \mathrm{q}$} & \multirow{2}{*}{ متوسط (سا - 11 ا درجة). } & $0 ., \cdot$ & VY & صغيرة (أقل من فدان). & - \\
\hline & & & $\varepsilon 1, v$ & 7. & متوسطة (فدان - أقل من r أفدنة). & - \\
\hline ro, & 01 & - - ـ مرتفع (19 - ع ع درجة). & $\wedge, r$ & ir & كبيرة (r أفدنة فأكثر). & - \\
\hline
\end{tabular}




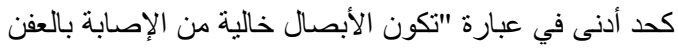

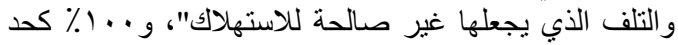

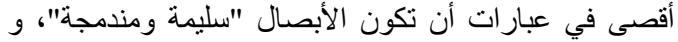

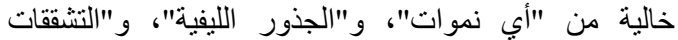

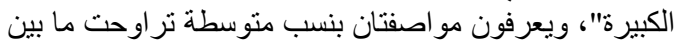

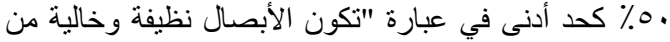

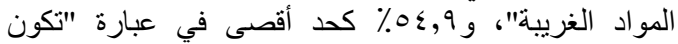

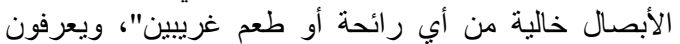

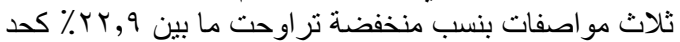

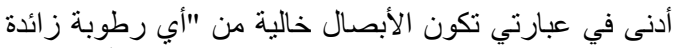

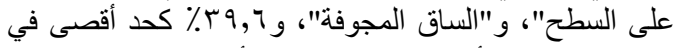

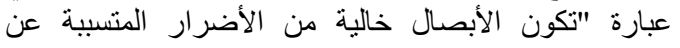

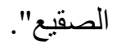

ثانيا: مستوى معرفة الزراع المبحوثين بالمواصفات التصديرية لمحصول البصل مئل

الـ مستوى معرفة الزراع المبحوثين بالمواصفات الخاصة بالجودة

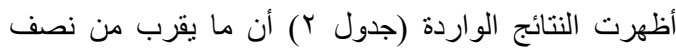

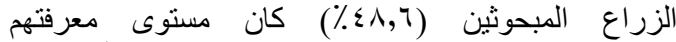

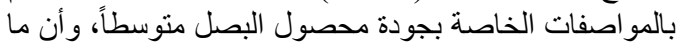

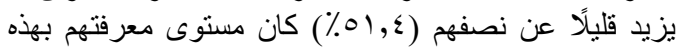

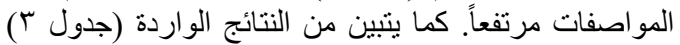

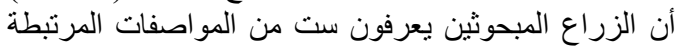

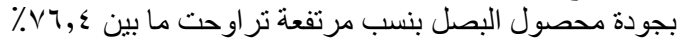

جدول (r): التوزيع العددي و النسبي للزر اع المبحوثين وفقاً لمستوى معر فتهم بالمو اصفات الخاصة بالجودة (ن= ؟ ؟ ).

\begin{tabular}{|c|c|c|}
\hline$\%$ & عدد & المستوى المعرفي \\
\hline$\cdot, \cdot$ & $\cdot$ & منخفض (1) - ؟ ( درجة). \\
\hline$\varepsilon \Lambda, \uparrow$ & v. & متوسط (10 ـ 11 ( درجة). \\
\hline $01, \xi$ & $V \varepsilon$ & مرتفع (19 - Y Y درجة). \\
\hline
\end{tabular}

جدول (r): التوزيع العددي و النسبي للزراع المبحوثين وفقاً لمعرفتهم بالمو اصفات الخاصة بالجودة (ن= ع ـ ).

\begin{tabular}{|c|c|c|}
\hline \multicolumn{2}{|c|}{ 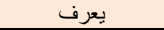 } & \multirow{2}{*}{ المواصفات الخاصة بالجودة } \\
\hline$\%$ & عدد & \\
\hline $1 \ldots$, & $1 \leq \varepsilon$ & تكون الأبصال سليمة ومندمجة \\
\hline $1 \ldots$, & $1 \leq \varepsilon$ & تكون الأبصال خالية من أي نموات (تزريع) \\
\hline $1 \ldots, \cdot$ & $1 \leq \varepsilon$ & تكون الأبصال خالية من حزمة الجذور الليفية \\
\hline $1 \ldots, \cdot$ & $1 \leqslant \leqslant$ & تكون الأبصال خالية من التشققات الكبيرة \\
\hline $\mathrm{vv,1}$ & 111 & تكون الأبصال خالية من أي تضخم (انتفاخ) بسبب النمو غبر الطبيعي \\
\hline$v_{\uparrow}, \varepsilon$ & 11. & تكون الأبصال خالية من الإصابة بالعفن و التلف الذي يجعلها غير صالحة للاستهلاك \\
\hline $0 \leqslant, 9$ & $\mathrm{v9}$ & تكون الأبصال خالية من أب رائحة أو طع غريبين \\
\hline $0 ., \cdot$ & VT & تكون الأبصال نظيفة وخالية من المواد الغريبة \\
\hline$r 9,7$ & ov & تكون الأبصال خالية من الأضرار المتسببة عن الصقيع \\
\hline$r, q$ & rT & تكون الأبصال خالية من أي رطوبة زائدة على السطح \\
\hline$r$ r,q & re & تكون الأبصال خالية من الساق المجوفة (الحنبوط) \\
\hline
\end{tabular}

المصدر: استمارة الاستبيان.

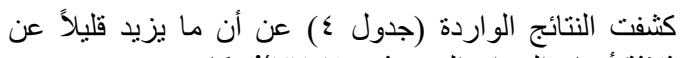

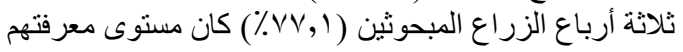

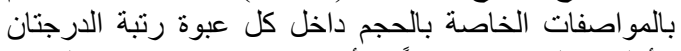

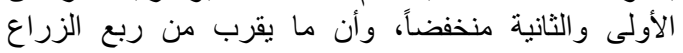

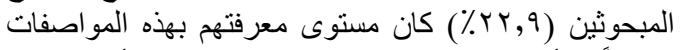

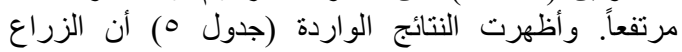

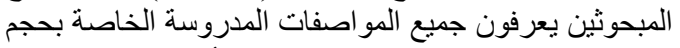

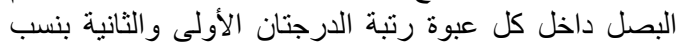

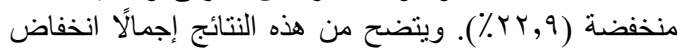

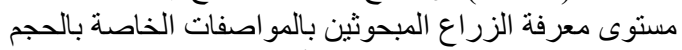

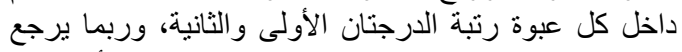

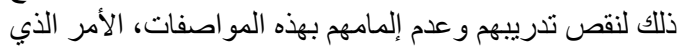

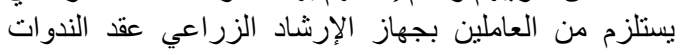

ويتضح من هذه النتائج إجمالًا أن نسبة لا يُستهان بها من بان

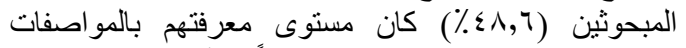

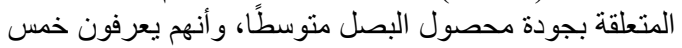

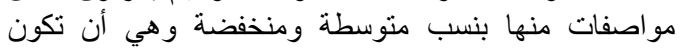

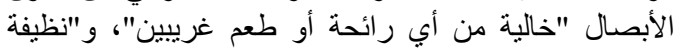

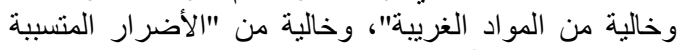

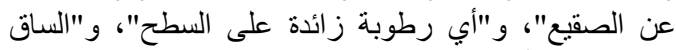

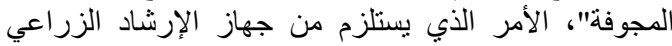

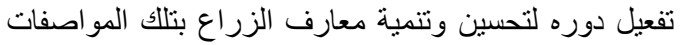

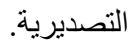

Y. بالمتوى معرفة الزراع المبحوثين بالمواصفات الخاصة بالحجم داخل كل عبوة رتبة الدرجتان الأولى والثانية 
Shakwar and Abdelhalim / Archives of Agriculture Sciences Journal 4(2) 93-104, 2021.

الإرشادية، و إجر اء الايضاحات العملية، و إمدادهم بالمعارف الدقيقة والمتخصصة المرتبطة بتلك المو اصفات التصديرية.

جدول (ء): التوزيع العددي و النسبي للزر اع المبحوثين وفقاً لمستوى معرفتهم بالمو اصـفات الخاصـة بـالحجم داخل كل عبوة رتبـة

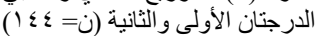

\begin{tabular}{|c|c|c|}
\hline$\%$ & عدد & المستوى المعرفي \\
\hline $\mathrm{VV}, 1$ & 111 & منخفض (ع - 0 درجات). \\
\hline$\cdot, \cdot$ & $\cdot$ & متو سط (T - V درجات). \\
\hline 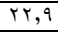 & rt & مرتفع (^ درجات). \\
\hline
\end{tabular}

المصدر: استمارة الاستبيان.

جدول (0): التوزيع العددي و النسبي للزر اع المبحوثين وفقاً لمعرفتهم بالمو اصفات الخاصة بـالحجم داخل كل عبوة رتبـة الدرجتان

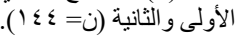

\begin{tabular}{|c|c|c|}
\hline \multicolumn{2}{|c|}{ 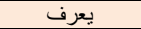 } & \multirow{2}{*}{ المو اصفات الخاصة بالحجم داخل كل عبوة رتبة الدرجتان الأولى والثانية } \\
\hline$\%$ & عدد & \\
\hline Y,$q$ & זr & 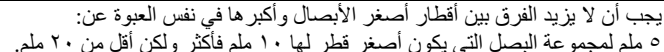 \\
\hline rY,q & rT & ما ملم لمجمو عة البصل التي يكون أصغر قطر لها . ب ملم فأكثر ولكن أقل من . ؛ ملح. \\
\hline rr,q & re & 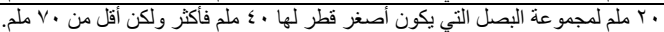 \\
\hline rY,q & Tr & • . ملم لمجمو عة البصل التي يكون أصغر قطر لها • V ملم فأكثر. \\
\hline
\end{tabular}

المصدر : استمارة الاستبيان.

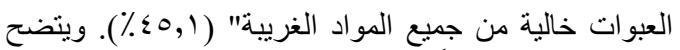

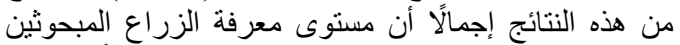

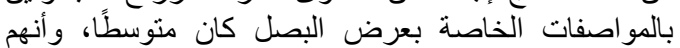

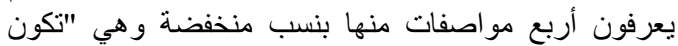

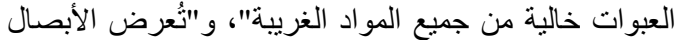

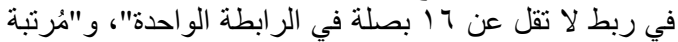

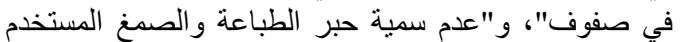

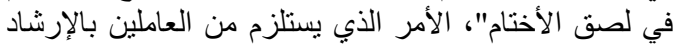

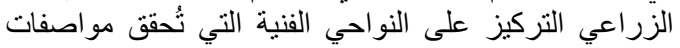

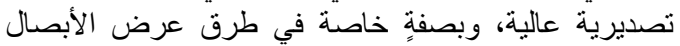

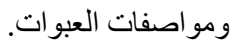

\section{؛. مستوى معرفة الزراع المبحوثين بالمواصفات الخاصة} بالعلامات

أظهرت النتائج الواردة (جدول ^) أن حوالي ثلاثة أخماس

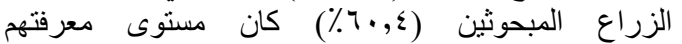

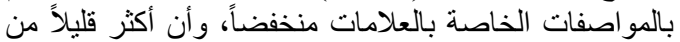

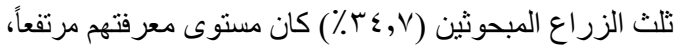

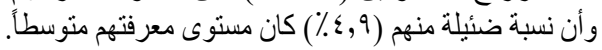

\section{r. معرفة الزراع المبحوثين بالمواصفات الخاصة بالعرض}

بينت النتائج الواردة (جدول 7) أن الغالبية العظمى من الزراع

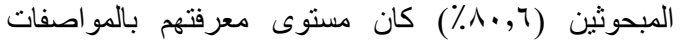

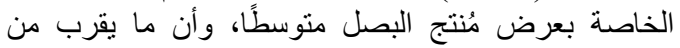

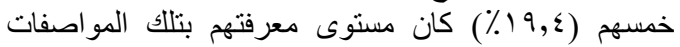

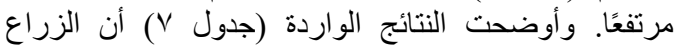

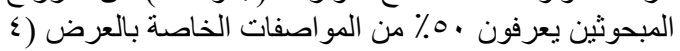

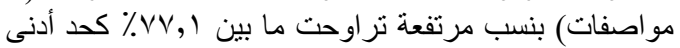

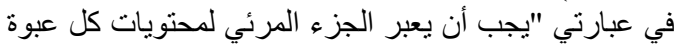

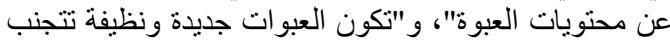

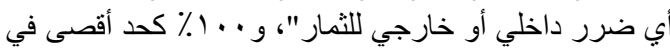

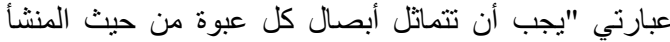

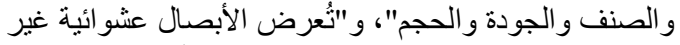

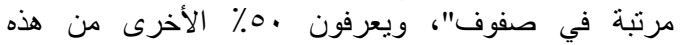

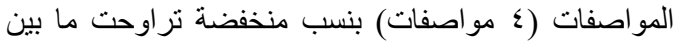

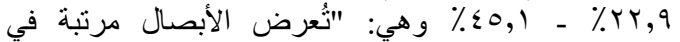

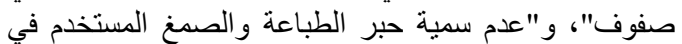

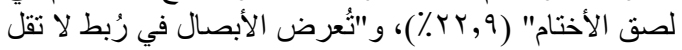

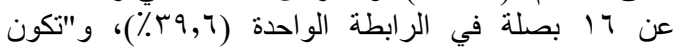

جدول (†): التوزيع العددي و النسبي للزر اع المبحوثين وفقاً لمستوى معر فتهم بالمو اصفات الخاصة بالعرض (ن= ؟ ؟ ().

\begin{tabular}{|c|c|c|}
\hline$\%$ & عدد & المستوى المعرفي \\
\hline$\cdot, \cdot$ & - & منخفض (^ - . أ درجات) \\
\hline$\lambda_{\cdot, \tau}, \tau$ & 117 & متوسط (1) - ז ا درجة) \\
\hline $19, \Sigma$ & rA & مرتفع (ـ ا ـ 17 درجة) \\
\hline
\end{tabular}

المصدر : استمارة الاستبيان. 
Shakwar and Abdelhalim / Archives of Agriculture Sciences Journal 4(2) 93-104, 2021.

\begin{tabular}{|c|c|c|}
\hline \multicolumn{2}{|c|}{ يعرف } & \multirow{2}{*}{ المو اصفات الخاصة بالعرض } \\
\hline$\%$ & عدد & \\
\hline $1, \ldots, \cdot$ & $1 \leq \varepsilon$ & يجب أن تتماتل أبصال كل عبوة من حيث المنشأ والصنف و الجودة والحجم \\
\hline $1, ., \cdot$ & $1 \leqslant \varepsilon$ & تُعرض الأبصال عشو ائياً (سائبة) غير مرتبة في صفوف \\
\hline$v \vee, 1$ & 111 & يجب أن يعبر الجزء الظاهري (المرئي) لمحتويات كل عبوة عن محتويات العبوة \\
\hline $\mathrm{vV}, 1$ & 111 & تكون العبوات جديدة ونظيفة تتجنب أبي ضرر داخلي أو خارجي للثمار \\
\hline$\varepsilon 0,1$ & 70 & تكون العبوات خالية من جميع المو اد التغريبة \\
\hline rq,7 & ov & تُعرض الأبصال في رُبط لا تقل عن 17 بصلة في الرابطة الو احدة \\
\hline rr,q & $r \mu$ & تُعرض الأبصال مرتبة في صفوف (طبقات) \\
\hline rr,q & $r \mu$ & عدم سمية حبر الطباعة و الصمغ المستخدم في لصق الأختام \\
\hline
\end{tabular}

المصدر: استمارة الاستبيان.

جدول (^): التوزيع العددي و النسبي للزر اع المبحوثين وفقاً لمسنوى معر فتهم بالمو اصفات الخاصة بالعلامات (ن= ؟ ؟ ( ).

\begin{tabular}{|c|c|c|}
\hline$\%$ & عدد & المستوى المعرفي \\
\hline $7 \cdot, \varepsilon$ & AV & منخفض (1 - ^ درجات) \\
\hline$\varepsilon, 9$ & $\mathrm{v}$ & متو سط (9 - • ( د درجات) \\
\hline$r \leqslant, \gamma$ & 0. & مرتفع (I| - r| درجة) \\
\hline
\end{tabular}

المصدر: استمارة الاستبيان.

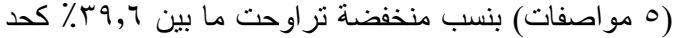

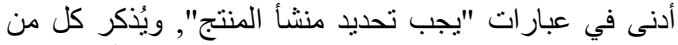

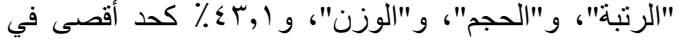
عبارة "يجب تحديد طبيعة المنتج في حالة المحتويات غير" الرئ

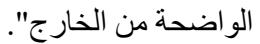

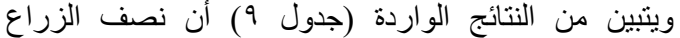

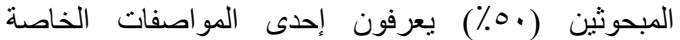

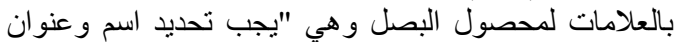

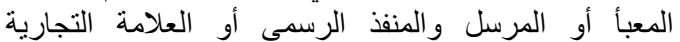
المقبولة"، و أنهم يعرفون الغالبية العظمى من هذه المواصفي الصفات

جدول (9): التوزيع العددي و النسبي للزر اع المبحوثين وفقاً لمعر فتهم بالمو اصفات الخاصة بالعلامات (ن= ع ـ ().

\begin{tabular}{|c|c|c|}
\hline \multicolumn{2}{|c|}{ يعرف } & \multirow{2}{*}{ المو اصفات الخاصة بالعلامات } \\
\hline$\%$ & عدد & \\
\hline $0 ., \cdot$ & VT & يُحدد اسم و عنوان المعبأ أو المرسل و المنفذ الرسمى أو العلامة التجارية المقبولة \\
\hline$\varepsilon r, 1$ & $\pi$ & طبيعة المنتج: بصل (في حالة المحتويات غير الواضحة من الخارج) \\
\hline$r 9,7$ & ov & منشأ المنتج: دولة المنشأو ومنطقة الزراعة \\
\hline$r 9,7$ & ov & تذكر الرتبة \\
\hline$r 9,7$ & ov & يذكر الحجم من خلال الحد الأدنى و الحد الأقصى للقطر \\
\hline$r 9,7$ & ov & 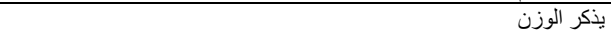 \\
\hline
\end{tabular}

المصدر: استمارة الاستبيان.

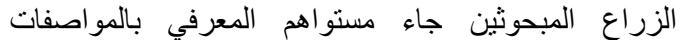
التصديرية المرتبطة بمحصول البصل مرتفئًا، وأما الغالبية

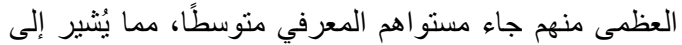

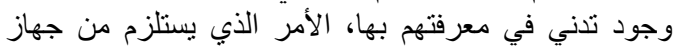

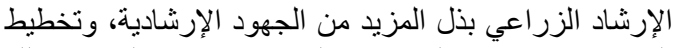

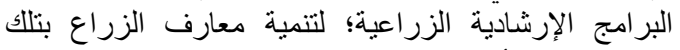

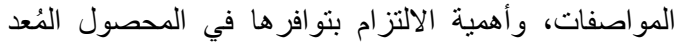
للتصدير.

\section{ثالثا: المشكلات التي تواجه زراع البصل المبحوثين}

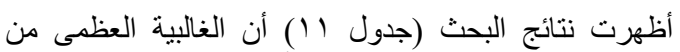

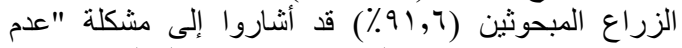

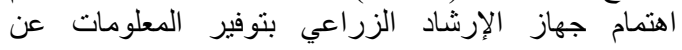

ويتضح من هذه النتائج إجمالًا انخفاض مستوى معرفة الزراع

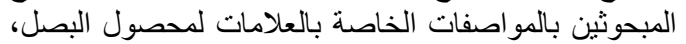

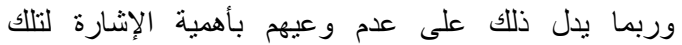

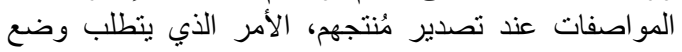

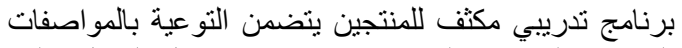

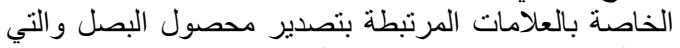

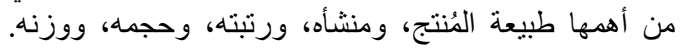

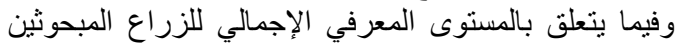

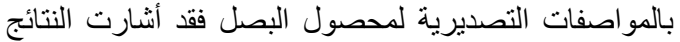

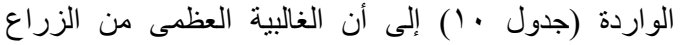

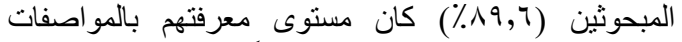

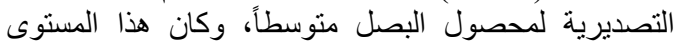

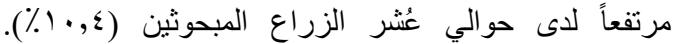

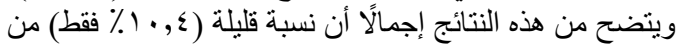




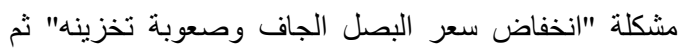

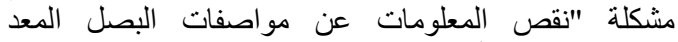

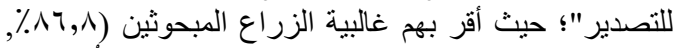

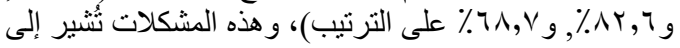

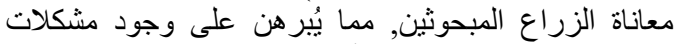

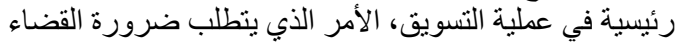

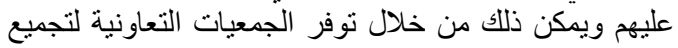

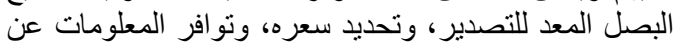
مو اصفات البصل المعد للتصدير للتصدير

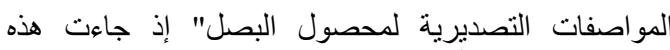

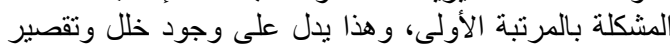

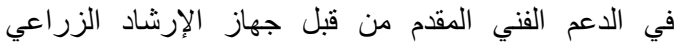

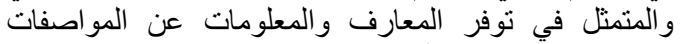

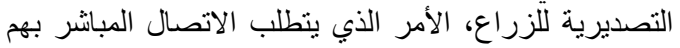
من خلال عقد الندوات الإرشادية المتخصية لإنصة في في هذا المجال وبالثكل الذي يُساهم في تحسين وتنمية مستوياتهم المعرفية.

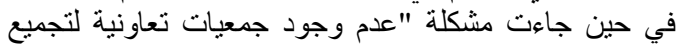
البصل المعد للتصدير" في المرتبة الثانية، تليها في الترتيب نئي

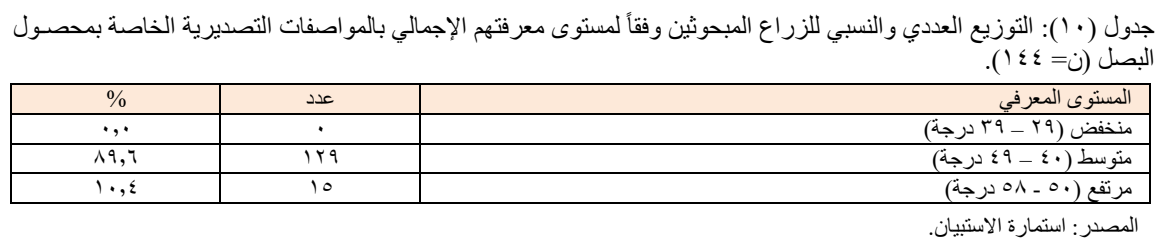

جدول (1 (1): التوزيع العددي و النسبي للزر اع المبحوثين وفقاً للمشكلات التي تواجهم (ن= ؛ ؛ ().

\begin{tabular}{|c|c|c|}
\hline$\%$ & عدد & المشكلات \\
\hline 91,7 & Tre & عدم اهتمام جهاز الإرشاد الزراعي بتوفير المعلومات عن المواصفات التصديرية لمحصول البصل. \\
\hline$\Lambda \mathrm{\Lambda}, \Lambda$ & Tro & عدم وجود جمعيات تعاونية لتجميع البصل المعد للتصدير \\
\hline$\overline{\Lambda \uparrow, \uparrow}$ & 119 & انخفاض سعر البصل الجاف وصعوبة تخزينه. \\
\hline $7 \curlywedge, \mathrm{V}$ & 99 & نقص المعلومات عن مو اصفات البصل المعد للتصدير. \\
\hline$\overline{7 r, \Lambda}$ & ar & ارتفاع أجور الأيدي العاملة و عدم توفرها. \\
\hline 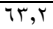 & 91 & عدم توفر أصناف ألبصل لأغراض للتصدير عند الزراعة. \\
\hline
\end{tabular}

المصدر : استمارة الاستبيان.

تفسيرٍ ذلك بأن صغار السن ربما يكونون أكثر معرفة

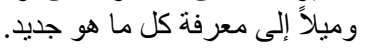

المستوى التعليمي: وجود علاقة ارتباطية طردية معنوية

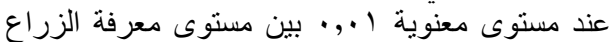

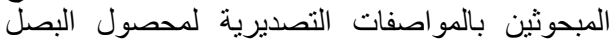

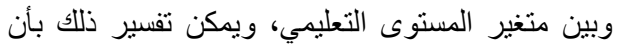

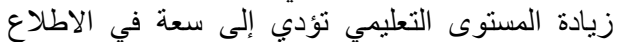

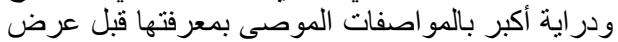
المنتج الزراعي في السوق، كما أن الثخص الثص المتعلم لديه قابلية للاستز ادة بالمعارف في النوف، والمعلو مات المات.

المساحة المنزرعة بالبصل: وجود علاقة ارتباطية

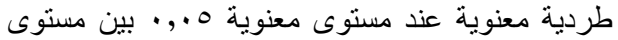

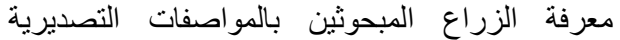

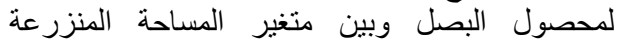
بالبصل، ويمكن تفسير ذلك بأن زيادة المساحة المنزر عة الميرة

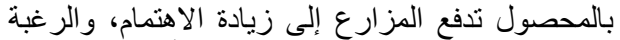

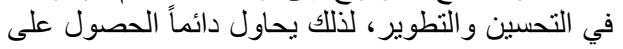
مزيد من المعارف و المعلومات.

عدد سنوات الخبرة في زراعة البصل: وجود علئ علاقة

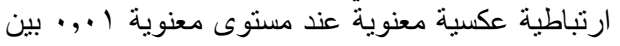

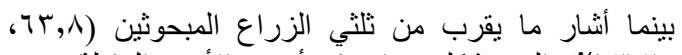

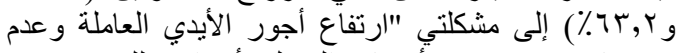

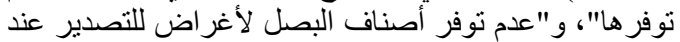

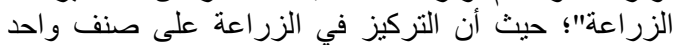

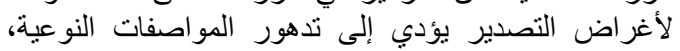

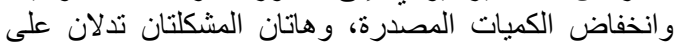

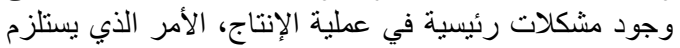

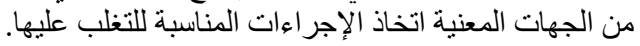

رابعا: العلاقة الارتباطية بين مستوى معرفة الزراع المبحوثين بالموصفات التصديرية لمحصول البصلة وبين الماين المتغيرات المستقلة المدروسة

تبنين من نتائج تحديد العلاقة الارتباطية بين مستوى معرفة

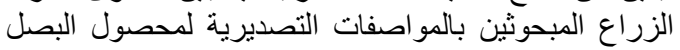

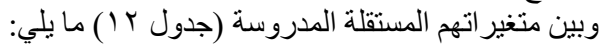

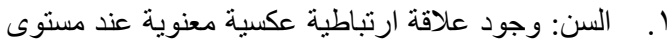

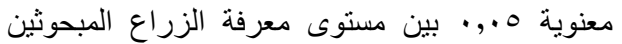

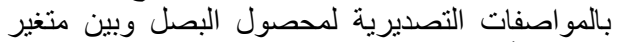

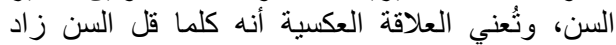

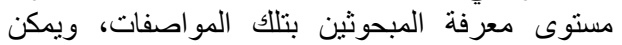


المعلومات، ويمكن تفسير ذللك بأن تعدد مصادر

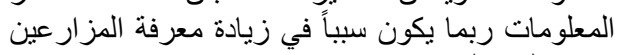
في مجال عملهم.

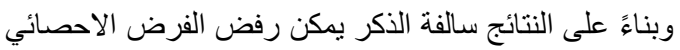

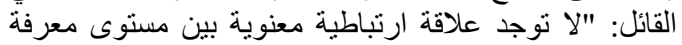

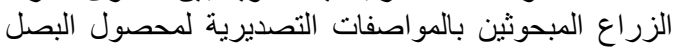

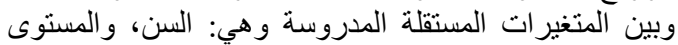

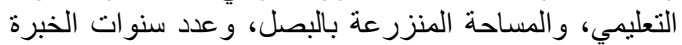

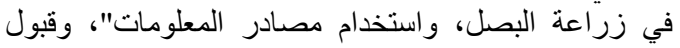

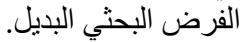

مستوى معرفة الزراع المبحوثين بالمواصفات

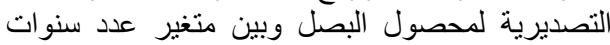
الخبرة في زر اعة البصل، ويمكن تفسير ذللك بأن حديثي

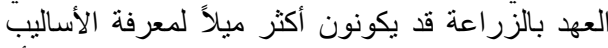

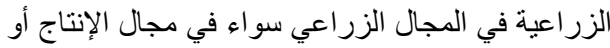

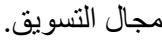

ه. استخدام مصادر المعلومات: وجود علدية علاقة ارتباطية

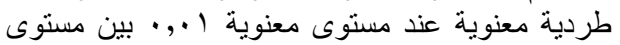

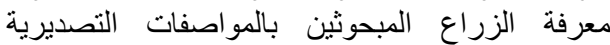
لمحصول البصل وبين متغير استخدام مصادر التئر

جدول (r ا ( ): قيم معامل ارتباط الرتب سبيرمان بين مستوى معرفة الزراع المبحوثين بالموصفات التصديرية لمحصول البصل وبين

المتغير ات المستقلة المدروسة.

\begin{tabular}{|c|c|}
\hline قيم معامل ارتباط سبير مان & المتغيرات المستقلة \\
\hline$*,, 1 \vee 7_{-}$ & السن \\
\hline$* * ., 010$ & المستوى التعليمي \\
\hline$* ., I V Y$ & المساحة المنزر عة بالبصل \\
\hline$* *_{.}, r V_{-}$ & عدد سنو ات الخبرة في زراعة البصل \\
\hline **., rTr & استخدام مصادر المعلومات \\
\hline
\end{tabular}

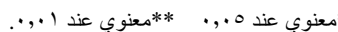

\section{قائمة المراجع}

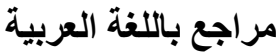

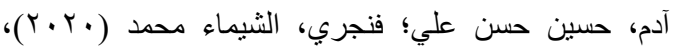

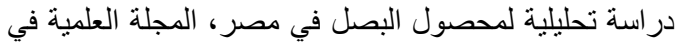

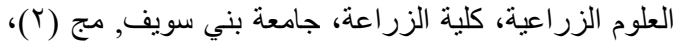

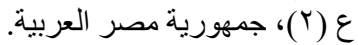

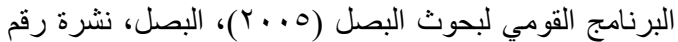

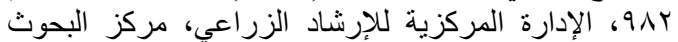
الزراعية، وزارة الزراعة واستصلاح الأراضي، الزي، جمهورية الزية

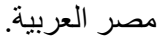

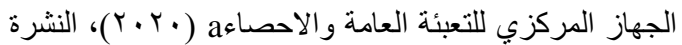

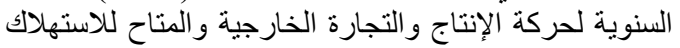

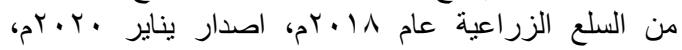
جمهورية مصر العربية.

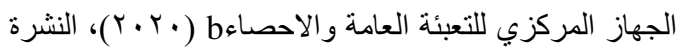

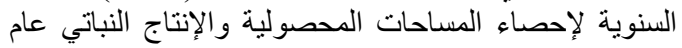

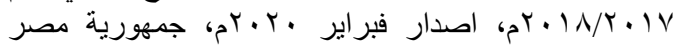

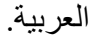

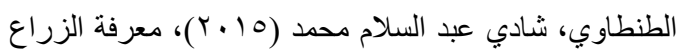

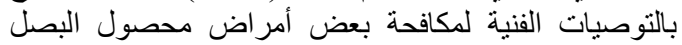

\section{توصيات البحث}

بناءً على النتائج التي توصل إليها البحث، يوصى بما يلي:

!. تكثيف الجهود الإرشادية الزراعية لتنمية وتحسين

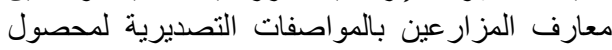

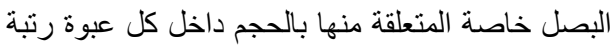
الدرجتان الأولى و الثانية، و العلامات.

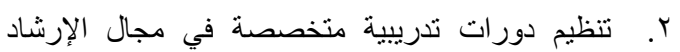
الزر اعي التسويقي لزر اع البصل.

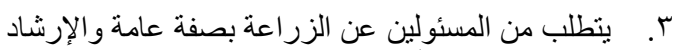

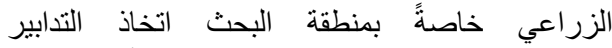

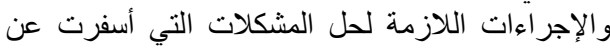

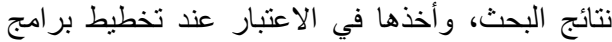
إرشادية زر اعية لزر اعنه البصل.

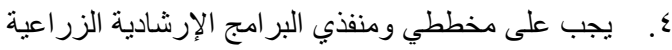

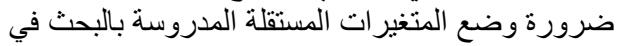

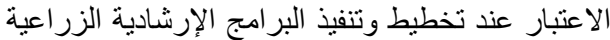

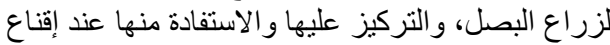

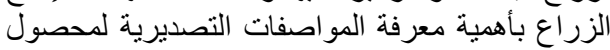
البصل؛ حيث بينت النتائج وجود علاقية الزئة ارتباطية بينها وبين المتغير التابع المدروس.

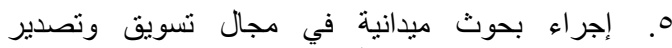
الحاصلات الزر اعية الأخرى المختلفة. 
الثنتوية، بيانات غير منشورة، الثئون الزراعية، الإدارة الزر اعية باسنا، مديرية الزر اعة بالأقصر . بأنون.

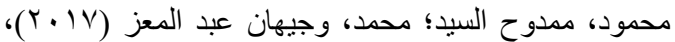
دراسة اقتصادية لأثر الممارسات الزراعية على على الفية الفاقد

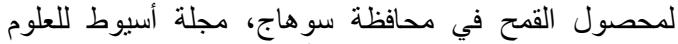

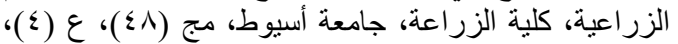
جمهورية مصر العربية.

مرجان، إيمان عز محمد، (د.ت)، نوطن محصول البصل في في البحري

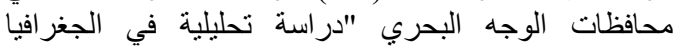

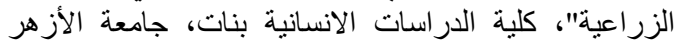
بالقاهرة، جمهورية مصر العربية.

مركز التجارة الدولي، والمعهة الفيزيائي التقني الاتحادي

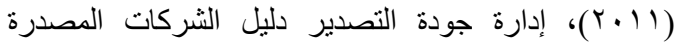

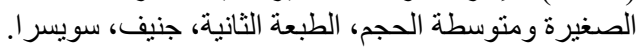

الفتيل في محافظة الغربية، مجلة العلوم الاقتصادية

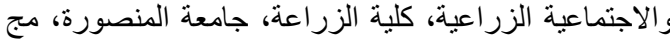
(7)، عدد (7)، جمهورية مصر العربية.

العبد، وائل أحمد عزت؛ عبد اللطيف، هناء شداد محمد؛

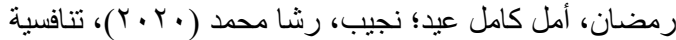

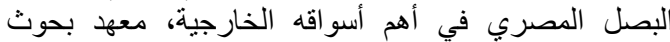

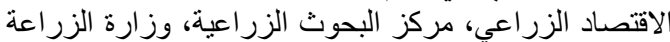
واستصلاح الأر اضي، جمهورية مصر العربية.

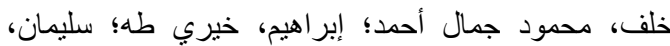

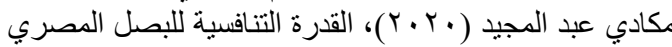

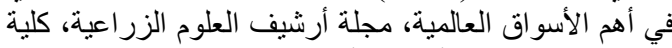

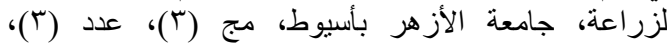
جمهورية مصر العربية.

قسم الإحصاء (YY.Y.Y)، البيان النهائي لحصر الدحاصيل

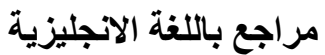

Krejcie, V. and Morgan, D. W. (1970), Determining sample size for research activities, Educational and Psychological Measurement, Vol. 30, pp. 607-610. 